IFAS Extension

\title{
Preparation of Puréed Foods ${ }^{1}$
}

\author{
Wendy J. Dahl and Jamila R. Lepore ${ }^{2}$
}

\section{What is a puréed food?}

A puréed food is a food item that has been blended, mixed, or processed into a smooth and uniform texture. Examples of foods with a purée consistency include applesauce, pumpkin pie filling, and hummus. Puréed foods may be necessary for people with chewing and/or swallowing problems (ADA, 2002).

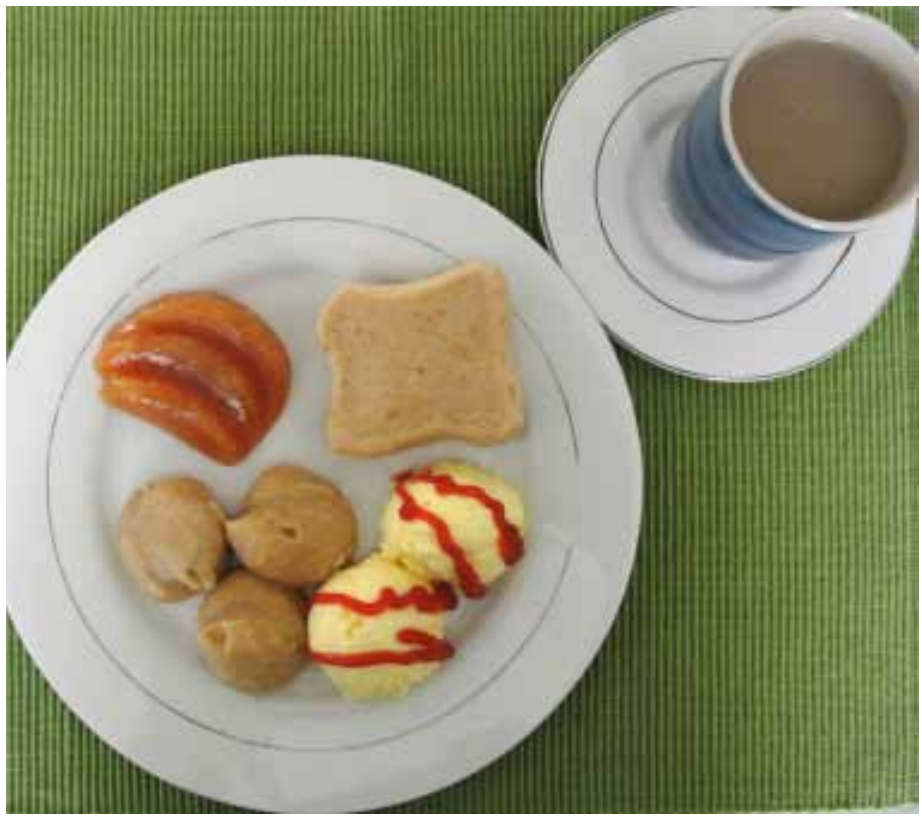

Figure 1. Scrambled eggs and ketchup with bacon, toast, peaches, and a side of coffee and milk

Credits: UF/IFAS
For those requiring a puréed diet, it is important to provide a variety of foods. Almost any food can be puréed. However, some puréed foods may be much more acceptable than others.

\section{Equipment to prepare a purée}

Foods may be puréed using a blender or food processor.

\section{Blenders}

- Best for liquid foods (milkshakes, sauces, fruit purées/ smoothies, soups)

\section{Food processors}

- Best for most foods (vegetables, meats, crackers/ breadcrumbs)

- Good for chopping, slicing, and shredding foods prior to puréeing

\section{Steps to prepare a puréed food}

1. Weigh or measure the number of portions required for the recipe. (Canned foods may need to be drained.)

2. Process items in a food processor until they are fine and homogenous in texture.

1. This document is FSHN12-12, one of a series of the Food Science and Human Nutrition Department, Florida Cooperative Extension Service, Institute of Food and Agricultural Sciences, University of Florida. Original publication date March 2013. Visit the EDIS website at http://edis.ifas.ufl.edu.

2. Wendy J. Dahl, assistant professor, and Jamila R. Lepore, graduate student; Food Science and Human Nutrition Department, University of Florida Institute of Food and Agricultural Sciences, Gainesville, FL 32611.

The use of trade names in this publication is solely for the purpose of providing specific information. UF/IFAS does not guarantee or warranty the products named, and references to them in this publication do not signify our approval to the exclusion of other products of suitable composition. 


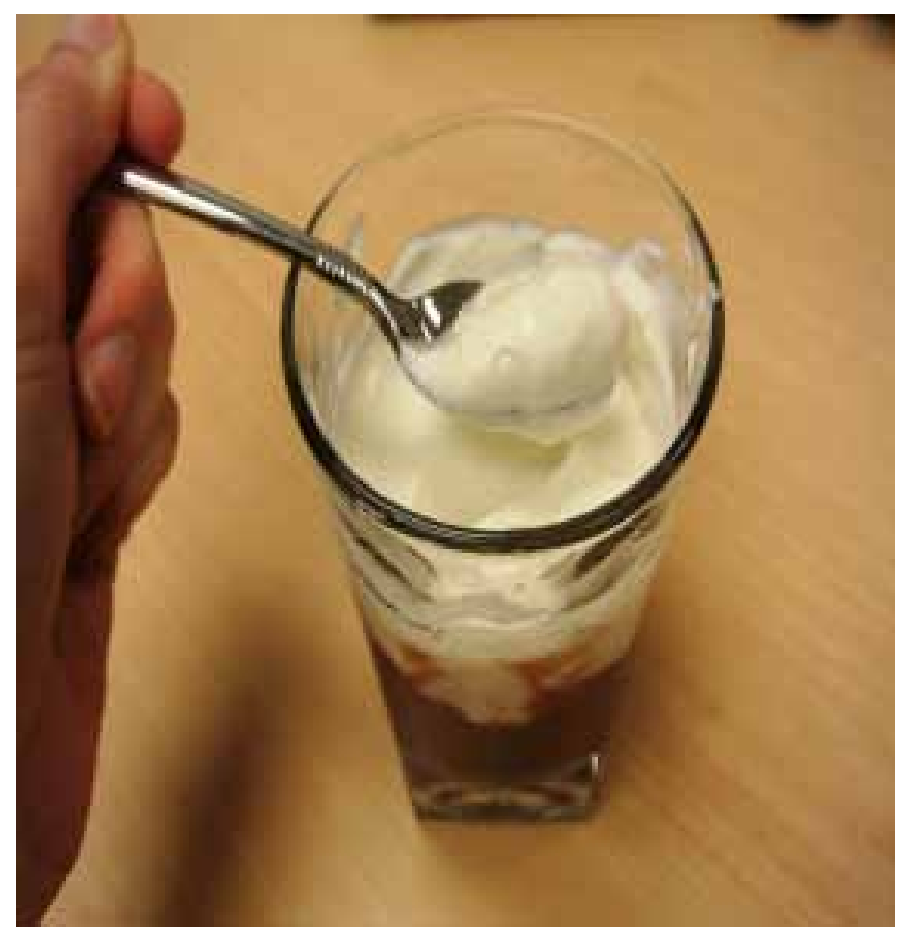

Figure 2. Dark chocolate mousse with sweet vanilla crème Credits: UF/IFAS

3. If the purée is too thick or too thin, take the necessary steps to get the purée to the proper consistency.

If too thick: Add measured amounts of hot liquid for cooked foods and cold liquid for cold foods. Add small amounts at a time so as not to make the purée too thin. Reprocess until smooth.

If too thin: Measure and add commercial thickener or natural food thickener (see below). Add small amounts at a time so as not to make the purée too thick.

4. Reprocess until smooth.

5. Add any flavors, herbs, or spices and process again until very smooth.

If serving immediately, portion purées with a scoop of appropriate size and garnish as desired. If shaping the purée, pour it into food molds. If storing for later use, refrigerate or freeze the purée following food safety guidelines.

\section{Finding the right consistency}

Preparing a puréed food with optimal texture is important for safe swallowing. A food may need to be thickened or thinned depending on individual recommendations.

Puréed foods that are too thin may be difficult for some people to swallow. It is often easier to control and swallow a thicker food because it moves more slowly through the swallowing process. Puréed foods that are too thick may also be difficult to swallow. It is very important to create palatable and "safe to swallow" purées that have the right consistency (i.e., not too thin and not too thick).

In general, a puréed food should have a uniform texture that is "spoon thick" and should not require chewing. It should not be dry, sticky, or lumpy. Consistency may need modification to suit individual needs.

\section{Why use thickeners?}

Thickeners are used in the preparation of puréed foods to prevent water separation and to keep the puréed food from being too thin or runny. There are several options for thickeners, including commercial and natural food thickeners. Commercial thickeners include starch- and gum-based thickeners. Natural food thickeners include finely crushed crackers, cereals, and puréed beans.

\section{Starch thickeners}

Starch thickeners are powders that are made of $100 \%$ modified starch. Examples of commercially available starch thickeners are Thick-It ${ }^{\oplus}$ and ThickenUp ${ }^{\oplus}$.

\section{Advantages}

- Simple to measure and mix into foods and beverages

- How-to guides are available to determine amounts to add to thicken various foods and beverages

\section{Disadvantages}

- Provides only starch and no other nutrients

- May create undesirable texture and off flavors

- May thicken over time, resulting in a product that is too thick

- May not mix well with very acidic foods and beverages (e.g., orange juice)

\section{Gum thickeners}

Gum thickeners are made primarily of xanthan gum and water. Commercial products include ThickenUp Clear ${ }^{\circledR}$ and SimplyThick ${ }^{\circledast}$. 


\section{Advantages}

- Provide no calories

- Simple to measure

- How-to guides are available to determine amounts to add to thicken various foods and beverages

- Do not thicken over time

\section{Disadvantages}

- May give undesirable off flavors

- May be difficult to achieve uniform thickening

- May not mix well with oral nutritional supplements (e.g., Ensure $^{\circledast}$ or Boost ${ }^{\circledast}$ )

- Not recommended for infants (FDA 2011)

\section{Other thickening options}

Blended or powdered foods often can be used to thicken purées, adding taste and nutrients. Examples include the following:

\section{Powders}

- Finely ground crackers/breadcrumbs/cookies

- Baby cereals

- Finely ground breakfast cereals

- Dried vegetable powders

- Potato flakes

\section{Purées}

- Puréed canned or cooked beans

- Puréed starchy vegetables (e.g., canned pumpkin, potato)

Advantages

- Provide additional nutrients, which are important for people with swallowing problems and limited food intake

- Produce a desirable texture that will not thicken over time
- Enhance flavor

\section{Disadvantages}

- No how-to guides are available; recipes must be developed to prepare tasty purées with the appropriate texture

\section{Goals of puréed food production}

1.Puréed foods should be made with very similar textural characteristics each time they are prepared and served. The best way to prepare puréed foods is to develop standard, tested recipes. Recipes are important to ensure the purée has an acceptable taste and texture. The texture should be smooth, cohesive, and the appropriate "spoon thick" consistency every time the puréed food is prepared. A spoon test can be used to test the consistency of small batches of food.

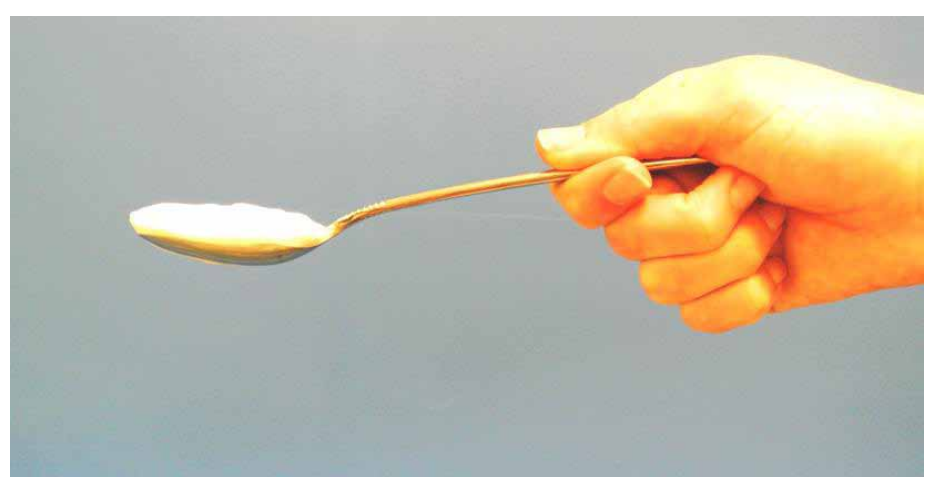

Figure 3. Example of "spoon thick" purée Credits: UF/IFAS

2. A yogurt- or pudding-like consistency is considered "spoon thick" and is the proper texture for purées.

3. Puréed foods should be prepared with optimal flavor, appearance, and aroma. If the food doesn't look or smell good, it probably will not be eaten. If the food passes the visual and aroma test, it probably will be.

Try edible garnishes with a suitable puréed texture to enhance the overall appeal of the purée. Excellent options include sauces, gravies, and any food or condiment of purée consistency that can improve appearance and flavor.

The acceptability of flavor and texture determines whether the purée will be eaten. Sensory testing and recipe development are the keys to ensuring that puréed foods are acceptable and appealing.

\section{Where can I get more information?}

The Family and Consumer Sciences (FCS) agent at your county Extension office may have more written information 


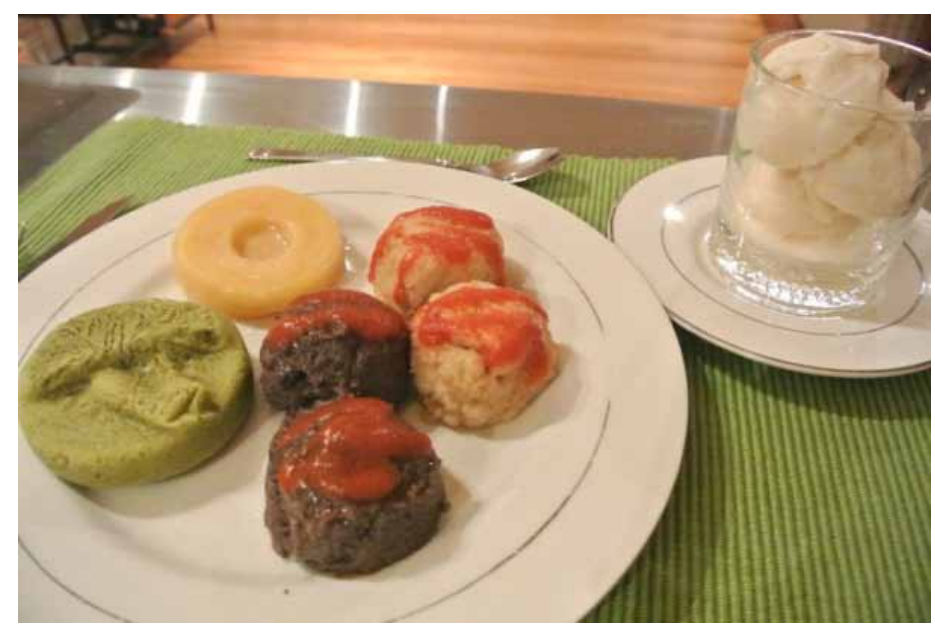

Figure 4. Spanish-style rice and beans with red chile sauce, a side of broccoli, pineapple, and vanilla frozen yogurt for dessert Credits: UF/IFAS

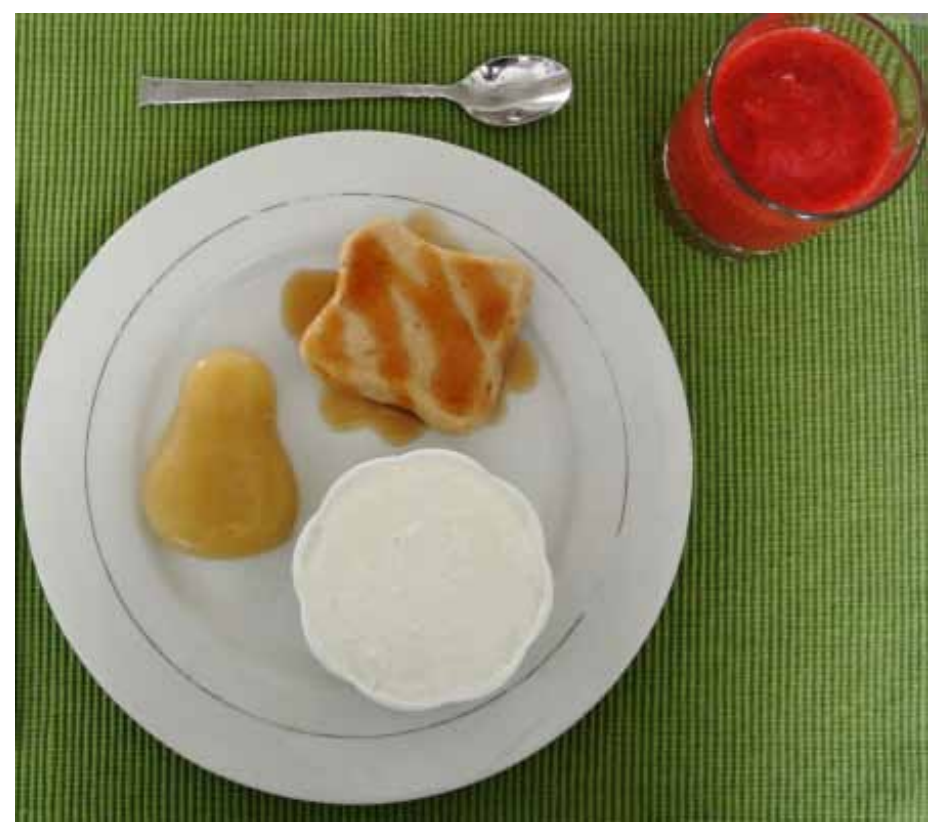

Figure 5. French toast and syrup with a side of cottage cheese and peaches and a strawberry yogurt smoothie Credits: UF/IFAS

and nutrition classes for you to attend. Also, a registered dietitian $(\mathrm{RD})$ can provide you with reliable information.

\section{Resources}

National Dysphagia Diet Task Force (2002). National Dysphagia Diet: Standardization for Optimal Care. Chicago, IL: American Dietetic Association.

FDA (U.S. Food and Drug Administration). 2011. "Recall - Firm Press Release: Simply Thick, LLC Announces the Voluntary Recall of Products Manufactured by Thermo Pac, LLC at Their Stone Mountain, GA Food Processing Plant." http://www.fda.gov/Safety/Recalls/ucm257841.htm. http://www.simplythick.com

http://www.thickitretail.com 